\title{
A definição e os tipos de discursos alternativos
}

The definition and types of alternative discourse

Syed Farid Alatas

\section{Introdução}

Este artigo inicia-se com o pressuposto de que a teoria da dependência acadêmica fornece um enquadramento adequado para a compreensão das relações entre as comunidades de ciências sociais no Norte e no Sul (Alatas, 2006: cap. 3). Sugiro que nós, acadêmicos, pouco podemos fazer a respeito das dimensões estruturais e materiais desta dependência, pois não estamos no comando das instituições e do Estado. Contudo, há muito a ser feito nos níveis intelectual e teórico. Nestes níveis, práticas culturais e tradições de conhecimento não-oci-

Agradecemos a Farid Alatas pela cessão de alguns de seus artigos para o Núcleo de Estudos Periféricos e Conexões Sul, para serem traduzidos ao português. A obra de Farid tem um grande reconhecimento internacional, e graças à receptividade das editoras da revista Estudos Históricos, este texto, traduzido e editado por Cláudio Pinheiro e João Maia, é o primeiro a ser publicado em português.

Syed Farid Alatas é professor do Departamento de Sociologia e do Departamento de Estudos Malaios da Universidade Nacional de Cingapura (alatas@nus.edu.sg).

Artigo recebido em 30 de junho de 2010 e aprovado para publicação em 27 de agosto de 2010. 
dentais podem ser consideradas como fontes potenciais para conceitos e teorias, o que iria diminuir a dependência acadêmica diante dos poderes globais das ciências sociais. Portanto, fica evidente que a emergência e o incremento dos discursos alternativos equivalem a um processo de universalização e internacionalização das ciências sociais. Também deve ficar claro que os discursos alternativos dizem respeito à boa ciência social, pois eles são mais conscientes da relevância dos contextos locais e dos problemas derivados do controle discursivo do poder pelas ciências sociais. Como tais, os discursos alternativos podem ser úteis para a própria ciência social ocidental. Estes discursos acreditam-se alternativos ao que consideram ser o caráter orientalista ou europocêntrico das ciências sociais do Norte, das quais as ciências sociais do Sul são dependentes. O artigo fornece exemplos do que podemos considerar discursos alternativos.

\section{O anseio por discursos alternativos}

O discurso sobre o estado das ciências sociais no Terceiro Mundo não emerge de um movimento intelectual, mas sim de um grupo diversificado de acadêmicos e ativistas de uma grande variedade de disciplinas nas ciências humanas. Seja o anseio por criatividade intelectual endógena (Alatas, 1981), por uma tradição autônoma de ciências sociais (Alatas, 2002), por descolonização (Boehmer, 1995; Zawiah, 1994), pela globalização (Bell, 1994; Hudson, 1977; Taylor, 1993), pela sacralização, pela nacionalização, ou ainda pela indigenização ${ }^{1}$ das ciências sociais (Atal, 1981), todos têm se mostrado preocupados com o orientalismo e o eurocentrismo, com a irrelevância dos discursos dominantes e com a geração de discursos alternativos.

Deve ser ressaltado, hoje em dia, que o eurocentrismo e o orientalismo nas ciências sociais não consistem em afirmações flagrantemente racistas ou preconceituosas, fundadas em dicotomias simplistas como Oriente-Ocidente, avançado-atrasado e civilizado-bárbaro. Na verdade, elas se traduzem no estatuto marginal de pensadores e conceitos não-ocidentais e nas construções problemáticas que são o resultado da imposição de conceitos e teorias europeias (Alatas, 2006: cap.6). Dois destacados exemplos desse programa no contexto asiático são a nacionalização e a "indigenização" das ciências sociais.

\section{A nacionalização das ciências sociais}

A definição de nacionalização das ciências sociais pode ser mais bem compreendida por meio do delineamento de exemplos proeminentes da China e de Taiwan. 
A sociologia foi introduzida na China no começo do século XX por intermédio da tradução do livro Study of Sociology, de Herbert Spencer, em 1903 (Gransow, 1985: 140; Gipouloux, 1989: 52). A disciplina foi abolida em 1952, e o materialismo histórico a substituiu (Gipouloux, 1989: 55-56). A teoria marxista deveria dar conta de todos os fenômenos políticos, econômicos, sociais e psicológicos (Lin, 1987: 127). A disciplina foi restabelecida em 1979 a partir da percepção de que o rápido crescimento econômico previsto para as duas últimas décadas do século XX, que vinha acompanhado por mudanças fundamentais em estilos de vida, valores e mentalidades, demandava a restauração da sociologia (Gipouloux, 1989: 56). A nacionalização da sociologia na China tomou a forma de "sinicização".2

Clamores por uma sociologia sinicizada têm sido ouvidos na China desde 1930, embora o que se entendesse por "sinicização" variasse enormemente. Para alguns, a sinicização significava pesquisa social orientada para a reforma da sociedade. Para outros, referia-se a estudos comparados de comunidades (Gransow, 1993: 101). Uma abordagem mais teórica via a sinicização como estando enraizada em uma cultura nacional chinesa (Gransow, 1993: 101-102). É esta última compreensão que corresponde à nacionalização das ciências sociais, porque envolve "a incorporação de aspectos específicos da sociedade chinesa na sociologia como uma disciplina" (Lin, 1987: 130). Deve-se distinguir essa definição do que fossem simplesmente as atividades intelectuais e profissionais de sociólogos na China.

Para Lin, a sinicização da sociologia deveria ser avaliada em função do grau de generalidade alcançado por características chinesas e de sua introdução na sociologia (Lin, 1987: 130). Essa noção passou a ser atacada por igualar cultura e cultura tradicional chinesa em termos neoconfucianos. Argumentava-se que era necessária uma escola chinesa de sociologia, uma sociologia nacional, que incorporasse elementos tradicionais, modernos, nacionais e estrangeiros (Gransow, 1993: 108). De acordo com outra linha de pensamento, o ressurgimento da sociologia chinesa deveria ser relacionado ao estabelecimento de uma sociologia marxista sinicizada (Cheng \& So, 1983: 484). O programa de sinicização seria legitimado pelas demandas de um socialismo de viés chinês.

Tal sociologia comportava três posições (Gipouloux, 1989: 60-61; Gransow, 1985: 145). A primeira era a sinicização dos objetos e métodos da sociologia, que se traduzia no estudo das leis de desenvolvimento da formação social que constituía a nação chinesa. A segunda envolvia a unidade entre teoria e prática com base marxista e experiências estrangeiras. Já a terceira posição inclinava-se para a indigenização da sociologia, mas insistia também na necessidade de internacionalização da disciplina. A sociologia chinesa mal tinha começado a se equipar com uma orientação que lhe fornecia especificidade e co- 
nhecimento da sociologia estrangeira, e a sociedade chinesa ainda era muito fragmentada (Gipouloux, 1989: 61).

A indigenização das ciências sociais tomou forma em Taiwan no começo da década de 1980. É interessante notar que naquele momento os termos indigenização (bentuhua) e sinicização (zhongguohua) eram intercambiáveis aos olhos dos observadores europeus. Enquanto a maioria dos escritores taiwaneses do período usava o termo "sinicização das ciências sociais", ${ }^{3}$ os comentários europeus sobre estes trabalhos utilizavam o termo indigenização (Schmutz, 1989; Gransow, 1993) para descrever o mesmo movimento (Chen, 1993, 1994).

Na verdade, a distinção é importante para os taiwaneses. C. K. Hsu notou que sinicização é a recontextualização da teoria ocidental tomando a China como ponto de referência. Taiwan, tendo sua própria história e cultura, bem como suas próprias necessidades de recontextualização, referia-se mais adequadamente a uma "indigenização" (Hsu, 1991: 35). ${ }^{4}$ Hsu daria ênfase a Taiwan como tópico central de uma ciência social indigenizada, daí a inadequação do termo sinicização. A recente mudança formal de nome da Associação Chinesa de Sociologia de Taipei para Associação de Sociologia Taiwanesa ${ }^{5}$ foi uma evidência simbólica desta posição. O uso do termo indigenização em todos estes casos é consistente com nacionalização, pois o Estado-nação é o ponto de referência.

\section{A indigenização das ciências sociais}

Entretanto, outros proponentes da indigenização sustentam que teorias e conceitos podem ser derivados das experiências históricas e práticas culturais de várias culturas não-ocidentais, seja cultura definida de forma contígua ao Estado-nação ou de qualquer outra forma (Enriquez, 1994; Fahim \& Helmer, 1980; Lee, 1979; Alatas, 1993a). Indigenização, contudo, é um termo amorfo. Não se refere nem a uma perspectiva teórica, nem a um movimento intelectual. Na verdade, é uma categoria frouxa que subsume os trabalhos de vários autores oriundos de uma ampla gama de disciplinas das ciências humanas, todos eles preocupados com o problema da irrelevância e com a geração de tradições científicas alternativas.

O projeto de indigenização visa contribuir para a universalização das ciências sociais não apenas reconhecendo, mas insistindo que todas as culturas, as civilizações e as experiências históricas podem ser consideradas como fontes de ideias. Isso é realizado a partir da auto-consciência a respeito da dependência 
cultural e do etnocentrismo (Kim, 1996). Se entendermos indigenização dessa forma, torna-se claro que ela é um pré-requisito para a universalização das ciências sociais e para a manutenção de padrões internacionalmente reconhecidos de excelência acadêmica. Na verdade, indigenização tem sido frequentemente definida nesses próprios termos. Na Coreia dos anos 1970, acadêmicos foram "despertados" para a necessidade de uma sociologia coreana mais criativa (Shin, 1994). ${ }^{6}$ Lá, indigenização refere-se ao procedimento que parte do desenvolvimento histórico da sociedade coreana em direção à teoria universal (Shin, 1994: 21), "[...] até o ponto em que podemos digerir e assimilar proveitosamente as coisas estrangeiras [...], tendo como pano de fundo cultural e social a realidade do país" (Kwon, 1979: 21). Sem projetos autóctones ao redor do mundo, é um conjunto de discursos nativos (ocidental) que domina. Ademais, o projeto indigenizador deve ser realizado ao nível das pressuposições ontológicas, epistemológicas e axiológicas, bem como da teoria empírica. Kyong-Dong Kim (1996) apresenta um inventário de exemplos de ciências sociais autóctones, baseadas em conceitos derivados da tradição clássica da China e da Coreia e em práticas encontradas na vida cotidiana do povo coreano.

\section{A definição de discursos alternativos}

Embora as várias demandas por nacionalização, indigenização, criatividade intelectual endógena, descolonização, globalização ou sacralização das ciências sociais possam ter diferentes nomes, todas elas compartilham do esforço para criticar e transcender os elementos eurocêntricos e orientalistas que informam as ciências sociais. Portanto, nós nos referimos a esses discursos como alternativos porque eles se colocam em contraste e em oposição ao que consideram ser os discursos dominantes, em sua maioria euro-americanos.

Assim, a ideia de "discursos alternativos", tal como apresentamos, deve ser entendida como um termo coletivo e descritivo, referido àquele conjunto de discursos que emergiu em oposição ao que se considerava ser a ciência social eurocêntrica e euro-americana. Todavia, os objetivos dos discursos alternativos não devem ser entendidos em termos negativos, isto é, como limitados a um descolamento em relação ao controle metropolitano neocolonial. Deve também ser entendido de forma positiva, em relação à contribuição dos sistemas de pensamento não-ocidentais para teorias e ideias. As práticas culturais e o pensamento não-ocidental devem ser vistos como fontes de teorização, do mesmo modo que o conhecimento ocidental não deve ser rejeitado in toto. Aqui há uma afirmação explícita de que teorias e conceitos podem ser derivados de experiência histórica e práticas culturais de várias culturas não-ocidentais, seja este conceito definido 
de forma contígua ao Estado-nação ou de quaisquer outras formas (Enriquez, 1994; Fahim \& Helmer, 1980; Lee, 1979; Alatas, 1993a).

Podemos então formular uma definição de discursos alternativos como sendo aqueles discursos informados por experiências históricas e práticas culturais nativas, do mesmo modo que as ciências sociais ocidentais o são. Ser alternativo demanda uma virada para a filosofia, epistemologia, história, arte e outros modos de conhecimento nativos, todos eles fontes potenciais de conceitos e teorias das ciências sociais. Acreditamos que tais atividades podem diminuir a dependência intelectual diante dos núcleos dominantes das ciências sociais no Atlântico Norte. Entretanto, muitos interessados ou proponentes dos discursos alternativos não acreditam que isso constitua uma rejeição da ciência social ocidental. Hetnne, por exemplo, sugere que a solução para o imperialismo acadêmico não é se livrar de forma definitiva de conceitos ocidentais, mas adotar uma compreensão mais realista das ciências sociais ocidentais, entendendo-as como reflexo de contextos históricos e geográficos particulares (Hettne, 1991: 39).

Se entendermos os discursos alternativos desta maneira, fica claro que eles são pré-requisitos para a universalização das ciências sociais e para a manutenção de padrões internacionalmente reconhecidos de excelência acadêmica. Deveria ser óbvio, portanto, que os discursos alternativos se referem à boa ciência. A ciência social dominante e suas alternativas críticas, que vieram então a se tornar parte do próprio mainstream, emergiram na Europa Ocidental e nos Estados Unidos como respostas originais e criativas às condições nas quais surgiram. Para além do fato de que essas teorias eram, das mais diversas formas, excessivamente eurocên tricas, as condições no Ocidente, e em quaisquer outros lugares, não eram comparáveis às existentes nos séculos XVIII e XIX. Os novos contextos exigem que se criem alternativas ao mainstream. O que se está chamando de alternativo é o que é relevante para seu ambiente, criativo, não-imitativo e original, não-essencialista, anti-eurocêntrico e autônomo em relação ao Estado e a outros grupos nacionais ou transnacionais (Alatas, 2006: 82-83).

Se entendermos discursos alternativos dessa forma, é possível imaginar que há uma necessidade do seu uso no próprio estudo das sociedades ocidentais, à medida que os problemas de falta de originalidade e criatividade afligem em geral também o Ocidente.

\section{Desenvolvendo discursos alternativos}

O problema com muitos textos escritos sobre esses temas é que há pouco trabalho orientado para a construção de teorias e conceitos alternativos, ao passo que há muita discussão sobre a necessidade de tais alternativas. 
Tendo definido discursos alternativos, é necessário agora ser mais concreto e específico por meio de exemplos que mostrem como seriam esses discursos. Cada um dos tipos de irrelevância - isto é, não-originalidade, redundância, imprecisão, inaplicabilidade, mistificação, mediocridade e alienação - podem afetar as ciências sociais em termos de meta-análise, metodologia, teoria, estudos empíricos, e ciências sociais aplicadas (Alatas, 2006). Assim, discursos alternativos ou ciência social relevante também podem ser gerados em cada um desses níveis. Entretanto, nas passagens abaixo meus exemplos limitam-se aos níveis teórico e metodológico.

Na verdade, há vários graus de "alternatividade" (alternativeness). No nível mais simples possível, as ciências sociais relevantes na Ásia insistiram na aplicação criativa e cuidadosa de conceitos e teorias ocidentais aos contextos locais. Um exemplo seria o trabalho de Karl Wittfogel, Despotismo oriental, no qual o autor desenvolve e aplica criativamente a teoria de Marx sobre os modos de produção asiáticos. De acordo com a sua análise, o controle centralizado sobre um recurso-chave como a água deu lugar a uma estrutura de classes particular e a um Estado burocrático caracterizado por uma forma extrema de despotismo. Tais impérios "hidráulicos", devido à centralização extrema, não tinham uma aristocracia independente, como a existente no feudalismo europeu (Wittfogel, 1957). Podemos não concordar com essa tese, mas o ponto que sustento aqui diz respeito à aplicação criativa de uma teoria originalmente ocidental à situação chinesa. Nesse caso, contudo, não podemos ainda falar em discursos alternativos se o mainstream não for interpelado, criticado e subvertido ou se um conjunto alternativo de conceituações e teorias não for apresentado.

Num nível superior de alternatividade - e, portanto, de universalidade -, métodos e teorias tanto locais como ocidentais são aplicados a contextos locais. Em outro nível de alternatividade e universalidade, métodos e teorias - sejam locais, ocidentais ou autóctones - podem ser aplicados também a um mesmo contexto.

Antes de começar a considerar alguns exemplos de cada nível de alternatividade, gostaria de enfatizar que a aplicação criativa de métodos e teorias ocidentais não deve ser considerada como algo de menor significação do que os discursos alternativos. O melhor exemplo que tenho em mente é a "culturologia" (culturology) de Huang Wen-Shan. Este é um dos raros momentos em que, no campo da teoria, um pensador asiático foi levado a sério pelos gigantes do pensamento ocidental. Huang era um defensor da delimitação de uma ciência singular dedicada ao estudo do fenômeno cultural, isto é, a culturologia. Entre seus trabalhos estão Collected Essays on Culturology (1939), Theoretical Trends of Culturology (1959), System of Culturology (1968), Essays on Culture (1972) e Introduction to Culturology (1989). 
Neste último, Huang discute o desenvolvimento histórico da culturologia, analisa aspectos das teorias de Alfred L. Kroeber e Leslie White e reflete sobre as perspectivas para a organização da culturologia como uma nova ciência. Pitirim Sorokin alinhava-se visivelmente às visões de Huang sobre a importância da culturologia, mas não subscrevia sua "excessiva ênfase nas diferenças e singularidades dos sistemas social e cultural e a preferência por um estudo de cada um destes sistemas sociais através diferentes ciências da culturologia e da sociologia" (Sorokin, 1966: 391). A despeito das críticas de Sorokin, os esforços de Huang para promover o campo da culturologia foram levados a sério e incorporados pelo sociólogo russo (Sorokin, 1966: 205, 389-391).

\section{O método local e as teorias aplicadas à realidade local}

Uma das histórias chinesas mais influentes, o Shih chi (Registros Históricos) de Ssu-ma Ch'ien (145? - 86? a. C.), baseia-se em uma historiografia marcadamente distinta das histórias ocidentais (Hardy: 1994). Ao descobrir que antigas histórias eram inadequadas à tarefa de escrever uma história compreensiva do mundo, Ssu-ma Ch'ien desenvolveu um novo método que dividia o passado em cinco sessões:

1) Doze Anais, que registravam os reinos e dinastias e seus governantes; 2) Dez Quadros, que correspondiam a eventos de uma cronologia única; 3) Oito Tratados, que ofereciam relatos de aspectos específicos da economia, sociedade e cultura; 4) Trinta Casas Dinásticas, que proviam relatos da ascensão e queda de grandes famílias e de suas fiefs; ${ }^{5}$ ) Setenta Biografias, que discutiam a história de indivíduos conectados por circunstâncias históricas, conexões familiares, ocupações, geografia etc. (Hardy, 1994: 21-22).

De fato, o Shih chi não atende a quatro dos requerimentos básicos da historiografia ocidental. Primeiramente, percebe-se a falta de unidade da voz narrativa. Há um importante gradiente de variações em cada capítulo e a ausência de uma voz única reconstruindo a história. Em segundo lugar, não há coerência consistente entre as narrativas. Em algumas sessões falta até mesmo uma estrutura narrativa clara, com começo-meio-fim, que conferisse in teligibilidade diante da multiplicidade e do caos de fatos. Terceiro: não há uma narrativa unificada. Para acompanhar, por exemplo, qualquer evento histórico em particular, os lei- 
tores precisam remeter-se a diversos capítulos e, assim, acessar os relatos relevantes. Quarto: há uma falta de consistência nas narrações. Há múltiplas narrativas da mesma história que, frequentemente, se contradizem mutuamente, resultando em diferentes versões do mesmo evento (Hardy, 1994: 24-25). Seria válido apresentar versões competitivas dentro de um mesmo relato histórico, como Ssu-ma Ch'ien parece fazer? Ou deveríamos nos esforçar por oferecer uma apresentação verdadeira do passado como na tradição ocidental? Penso que não estou em posição de responder a essa indagação. O ponto, contudo, é, como nota Hardy, que Shih chi não é apenas um desafio, mas um contra-exemplo da historiografia ocidental (Hardy, 1994: 35).

Outro exemplo, desta vez teórico, seria o conceito de "redes graduadas", de Hsiao-t'ung, desenvolvido para explicar a prevalência do egoísmo entre os camponeses da China pré-revolucionária (Lee, 1992: 84). De fato, essa ideia seria muito importante ao considerarmos que as teorias sociais chinesas diferem significativamente das teorias sociais ocidentais, já que não se baseiam em uma dicotomia tradicional-moderno. A ausência de tal dicotomia foi a base para a visão de que o desenvolvimento industrial da China moderna assentava-se nas empresas individuais, encontradas em milhões de vilas, e que essa industrialização deva ser descentralizada em áreas rurais, ao invés de concentrada em centros urbanos (Gan, 1994).

Consideremos também o exemplo do conceito de min-joong. Esse é um termo que guarda certa semelhança com o conceito gramisciano de "subalterno". Os trabalhos de intelectuais do pós-colonialismo, tal como exemplificado no trabalho dos intelectuais dos chamados estudos subalternos, ${ }^{8}$ partem de um discurso modernizador naquilo que consideram como o desafio de reverter compreensões elitistas da historiografia e substituí-las por perspectivas subalternas (Prakash, 1992: 8). Ao fazê-lo, localizam "a ação da mudança no insurgente ou 'subalterno"' (Spivak, 1987: 197). Similarmente, min-joong refere-se àqueles que são politicamente oprimidos, economicamente explorados e contra os quais pesa discriminação social (Han, 1992: 439). Esse grupo não corresponde exatamente ao proletariado, já que inclui membros da classe média que são vitimados de várias formas e que se identificam com as massas (Han, 1996).

Outro exemplo de teorias derivadas de tradições locais vem dos estudos de comunicação na Ásia. Intelectuais chineses, japoneses e coreanos têm olhado para conceitos "indígenas" como bao (reciprocidade, em chinês), bian (mudança, em chinês), guanxi (inter-relação, em chinês), ke qi (polidez, em chinês), miantz (face, em chinês), amae (expansão da mensagem e das necessidades de aceitação da mensagem, em japonês), enryo-sasshi (formas de comunicação interpessoal, em japonês), en (relação predestinada, em japonês), omoiyari (sen- 
sibilidade altruística, em japonês) e uye-ri (reciprocidade complementar ou obrigatória, em coreano) (Chen, 2006: 8).

Nesse aspecto, seria importante reconhecer as fontes de teorias e conceitos de dentro do domínio das experiências históricas e das práticas culturais locais. É importante aqui, ademais, atentar para a distinção feita por Kim Kyong-Dong no contexto das ciências sociais coreanas entre a tradição clássica (confucionismo, filosofia etc.) e o mundo do discurso popular, distinção que sugere duas vias. ${ }^{9}$ Exemplos da utilização do primeiro como um recurso para a teorização estariam na dialética ying-yang (Kim, 1994a) e no desenvolvimento de um modo de análise crítico da "ética confucionista" (Kim, 1996, 1994b).

Kim fez uma importante contribuição ao ultrapassar o uso do confucionismo como um tema de estudos para considerar o confucionismo como um artifício de conceitualização. Ele se refere, por exemplo, ao uso consciente e inconsciente de elementos confucionistas de construção do Estado pela elite governante para a racionalização da prática de governo centralizada e autoritária. Simultaneamente, Kim também usa o enquadramento geral de análise baseado na ideia da dialética ying-yang. Nesse enquadramento, democratização e liberalização são vistas como termos de uma "interação dialética entre forças que tentaram reter o poder de monopolizar a tomada de decisões e influenciar outros e forças que tentam mudar a distribuição de poder e influencia a vigente" (Kim, 1991: 138). O desafio aqui seria desenvolver um modo de análise dialético que seja diferente dos existentes.

O mundo do discurso popular como um recurso para as teorias sociais e conceitos científicos remete a ditados e terminologias do discurso popular e da linguagem cotidiana que não apenas refletem a herança cultural, mas também as percepções culturais de fenômenos sociais particulares (Kim, 1995: 173). Um exemplo do trabalho feito por Kim nessa démarche é o estudo de imagens culturais do ser velho e da velhice na Coreia, tendo como referência provérbios e ditos coreanos (Kim, 1995).

Nesse ponto é importante afirmar que a geração de teorias e conceitos a partir de culturas e práticas locais deve ser considerada como uma contribuição para a ciência social universal. Como explicado por Chen (2008: 13-14), esses conceitos são simultaneamente êmicos e éticos. Muitos fenômenos nas ciências sociais requerem uma conceituação êmica, devido à maneira particularista na qual são expressos e experimentados. Contudo, devido à sua universalidade, há ainda um nível no qual esses conceitos são éticos. O conceito de face, por exemplo, existe em todas as sociedades. Pesquisas mostram que o significado de face e as regras que determinam seu comportamento diferem de cultura para cultura. Nesse nível o conceito de face é êmico. Entretanto a pesquisa também mostra que a face ocupa o mesmo papel em todas as culturas. Esse é o nível no qual a face 
é um conceito ético (Chen, 2008: 14). Na medida em que a pesquisa com conceitos êmicos enriquece nossa compreensão do ético, e que há um relacionamento dialético e dialógico entre os dois (Chen, 2008: 19), a contribuição se dá pela universalização dos conceitos.

\section{Aplicação de uma teoria ocidental e não-ocidental a uma realidade local}

Um exemplo disso é a aplicação da teoria histórica da formação do Estado de Ibn Khaldūn, que incorpora conceitos e teorias da ciência social ocidental. Ibn Khaldūn estudou a formação e o declínio dos Estados norte-africanos, para os quais desenvolveu uma teoria original. Depois de observar as diferenças na organização social das sociedades nômades (ùmrān badāwi) e das sedentárias ( ùmrān hadārī), depreendeu a evolução natural da civilização nômade para a civilização sedentária, visto que "a cultura sedentária é o objetivo da vida beduína" e “o objetivo da civilização é uma cultura sedentária e refinada" (1378/1981:371 [1967, vol 2: 291]). ${ }^{10}$ Fundamental para essa teoria é o conceito de `asabiyyah ou sentimento de grupo. Somente uma sociedade com forte `asabiyyah poderia dominar outras (1378/1981:139, 154 [1967, Vol.1:284, 313]). Aqui, ‘asabiyyah refere-se ao sentimento de solidariedade entre os membros de um grupo que é derivado do conhecimento de que eles compartilham uma mesma descendência. Além da descendência, contudo, há outras considerações. Considerando que os beduínos possuíam `asabiyyah superior, eles poderiam superar os grupos sedentários e estabelecer suas próprias dinastias. Uma vez que eles se tornaram parte de populações assentadas e vivendo em áreas urbanas, cresceram acostumados aos modos de vida urbana e gradualmente experimentaram uma erosão de sua 'asabiyyah. Isso, por sua vez, afetou sua força militar e sua habilidade de governar. Sua posição enfraquecida significou que eles eram vulneráveis a ataques de novos grupos pré-urbanos de beduínos, dotados de uma `asabiyyah relativamente mais forte.

Em um trabalho anterior sobre Ibn Khaldūn, indiquei um caminho para a integração de uma perspectiva de modo de produção na teoria khaldūniana sobre a formação do Estado, considerando, como campo de aplicação, a história iraniana. Enquanto o sistema econômico safávida do Irã foi lido em termos de conceitos marxistas, suas dinâmicas têm sido descritas nos termos das teorias sobre formação do Estado desenvolvidas por Ibn Khaldūn. A economia política safávida pode ser caracterizada em termos de um modo de produção tributário como o dominante em um sistema-mundo secundário baseado no Estado. $\mathrm{O}$ trabalho de Ibn Khaldūn oferece um quadro teórico mediante o qual podemos 
compreender o surgimento e as dinâmicas do império global dos Safávidas (Alatas, 1993b).

\section{Aplicação de teorias locais e ocidentais a realidades locais}

Contudo, as aplicações da teoria de Ibn Khaldūn não deveriam estar confinadas a sociedades árabes, norte-africanas ou da Ásia ocidental. As dinâmicas de formação e declínio do Estado elaboradas dentro dos quadros desse modo de produção khaldūniano podem também ser reconsideradas em termos de enquadramentos de tempos históricos daquilo que Turchin denomina de "ciclo de Ibn Khaldūn" (Turchin, 2003: 173-196; Turchin \& Hall, 2003), e aplicadas à história da China e da Ásia Central. Essa é uma onda secular "que tende a afetar as sociedades com elites originadas de grupos nômades adjacentes" e que opera em uma escala de tempo de aproximadamente quatro gerações ou um século (Turchin \& Hall, 2003: 53). Eles discutem quatro dinastias Chinggisid que se enquadram na teoria khaldūniana de ascensões e quedas cíclicas de Estados: a dinastia Yuan da China, os Jagatai do Turquestão, os Il-Khans do Irã, e os Juchids das estepes de Kipchak. Todas essas dinastias passaram pelo ciclos khaldūnnianos típicos, de aproximadamente cem anos.

\section{Aplicação de teorias não-ocidentais a realidades locais}

Outro nível de alternatividade refere-se à aplicação de ideias geradas em uma sociedade não-ocidental e aplicadas a outra sociedade não-ocidental. Um exemplo é o esforço do sociólogo indiano Benoy Kumar Sarkar, que rejeita a dicotomia estereotipada sobre as religióes chinesas e indianas em favor da ideia de uma unidade asiática das religiões. Esse era o tópico de sua pesquisa em Chinese Religion through Hindu Eyes. De acordo com a dicotomia,

[...] "a engenhosidade da raça hindu é essencialmente metafísica e não-secular, [enquanto] os chineses são uma nação altamente pragmática, sem nenhum impulso transcendental. Os povos da Índia são acusados de cultivarem exclusivamente as ideias e sentimentos baseados em conceitos do Eterno, Infinito e do Devir; por outro lado, para o povo chinês, "o valor da moralidade obscureceu completamente as demandas de crença; obrigações com os vizinhos substituíram a precedência de obrigações em relação a Deus"(Sarkar, 1916/1988: 1). 
Sarkar propõe o estudo sistemático da sociologia asiática que envolveria o estudo histórico e comparado do budismo sino-japonês e do hinduísmo moderno com o intuito de provar a hipótese de que os budismos na China e no Japão são variedades da mesma fé, conhecida como hinduísmo tântrico e purânico (Sarkar, 1988 [1916]: 304).

\section{Teoria universal desenvolvida localmente}

O nível mais alto de alternatividade e universalidade refere-se à aplicação de teorias geradas localmente, integradas tanto a teorias não-ocidentais quanto a ocidentais, para realidades locais e extra-locais. Um exemplo disso é a teoria khaldūniana. Do ponto de vista da Ásia Oriental, contudo, a teoria khaldūniana é um exemplo de teoria não-ocidental integrada à teoria ocidental, tendo aplicação possível à realidade local. E como poderíamos considerar as teorias originadas na Ásia, no Extremo Oriente ou na China, que possuem, de fato, o potencial para aplicação universal? Já mencionamos acima a história de Ssu-ma Ch'ien. Nesse exemplo, o método dos estudos históricos que foi confinado à China também poderia ser aplicado ao estudo de outras histórias. Outro exemplo importante de teorias potencialmente universais que emergiram de contextos locais vem do pensador filipino do século XIX, José Rizal.

José Rizal (1861-1896) foi um pensador que teorizou o desenvolvimento social e político de uma forma original, não realizada, anteriormente, por seus pares ocidentais. Ainda que tenha vivido durante o período de formação do Ocidente e, particularmente, das ciências sociais europeias, Rizal desenvolveu uma perspectiva muito singular na apreciação da dimensão colonial na modernização da sociedade filipina do século XIX. Ele foi original ao considerar tanto os problemas que levanta, como no tratamento dado a eles. Um caso em particular é seu tratamento da questão da "indolência" dos filipinos. Ainda que não fosse um sociólogo tout court, Rizal conseguiu construir uma teoria sociológica através de seus trabalhos, que consistiria em três áreas. Primeiro, investe em uma crítica acerca da construção colonial espanhola da sociedade e da história filipinas. Posteriormente, numa teoria da natureza e das condições da sociedade colonial. Finalmente, discute o significado e as necessidades da emancipação. No pensamento de Rizal, o corrupto governo colonial espanhol e seus oficiais oprimem e exploram os filipinos, enquanto imputam o atraso das Filipinas à alegada preguiça de seu povo. Contudo, o projeto de Rizal era mostrar que os filipinos eram, de fato, uma sociedade relativamente avançada nos tempos pré-coloniais e que seu atraso era um produto do colonialismo. ${ }^{11}$ 


\section{Conclusão}

Identificar o anseio por discursos alternativos nas ciências sociais asiáticas não significa sugerir que a Ásia seja uma entidade culturalmente homogênea e que possa haver um ramo peculiar das ciências sociais na Ásia. O que isso sugere, contudo, é que as ciências sociais, tanto quanto outras formas de conhecimento, são sociais e históricas por natureza. Sugere, ademais, que as ciências sociais produzidas em muitas sociedades da Ásia devem se tornar relevantes para realidades históricas e sociais (Lee, 1996). Uma forma desse projeto ser atingido seria recorrer tanto às tradições filosóficas quanto aos discursos populares dessas sociedades para desenvolver teorias e conceitos científicos relevantes e originais para as ciências sociais.

Isso faz parte de um esforço para criar uma ciência social livre da dependência cultural e do etnocentrismo e que seja verdadeiramente universal (Kim, 1996). O objetivo, portanto, não é o de substituir o eurocentrismo por outra ciência social igualmente etnocêntrica. $O$ pressuposto de que existam conceitos e teorias aplicáveis somente ao fenômeno asiático implica que asiáticos e não-asiáticos fossem tão diferentes uns dos outros que demandariam universos teóricos separados para explicá-los. Como ressalta Kuo, tal argumento resultaria em pesquisadores colocando-se no mesmo dilema no qual eles colocaram os intelectuais europeus (Kuo, 2008: 9).

Também é necessário evitar, na crítica às ciências sociais tal como configuradas no Ocidente, homogeneizar o pensamento ocidental. ${ }^{12}$ Conforme Burawoy observou, há paralelos entre tradições no pensamento ocidental e as alternativas que vêm sendo propostas no Sul. Por exemplo, a teoria crítica feminista e a de raça poderiam ser consideradas uma forma de discurso alternativo tanto quanto os escritos de Ibn Khaldūn ou José Rizal.

Por vários anos, compartilhei, com a colega Vineeta Sinha, a docência de uma disciplina de sociologia clássica, no Departamento de Sociologia da Universidade Nacional de Cingapura. O programa desse curso refletia sobre o reconhecimento do problema tanto do eurocentrismo quanto do androcentrismo nas rotinas de ensino das ciências sociais. Um dos motes do curso era mostrar aos estudantes que, além dos homens brancos europeus - como Marx, Weber e Durkheim - havia também mulheres brancas europeias, além de homens e mulheres não-europeus e não-brancos que, no século XIX, teorizaram sobre a natureza das sociedades modernas emergentes (Alatas \& Sinha, 2001). ${ }^{13}$

De fato, lecionar essa disciplina terminou sendo a base para o reconhecimento de que há tradições alternativas ao mainstream dentro do próprio Ocidente. Além disso, apontamos para nossos estudantes, ao longo dos anos, que o Ocidente não deveria ser compreendido em um sentido ocidentalista, mas apenas 
como uma categoria oportuna para referir-se ao núcleo duro das ciências sociais das potências centrais, como os Estados Unidos, Grã-Bretanha e França (Alatas, 2006: 39, nota 1).

Os problemas estruturais que dificultam o esforço de criar discursos alternativos e tradições autônomas em ciências sociais - ou seja, contrapor a dependência acadêmica - têm sido discutidos tendo a nação com a unidade da análise. Isso posto, Burawoy pergunta qual é a base de crítica e o fundamento social que os discursos alternativos teriam. Minha resposta imediata é que fundamento social é tão nacional como transnacional. A luta por discursos alternativos está precisamente na tensão entre a necessidade de ser relevante diante de condições locais, nacionais ou regionais, por um lado, e o desejo de produzir ideias universais, por outro.

Também é necessário evitar uma visão homogeneizadora das ciências sociais. Como apontado por Burawoy, há diferenças entre as ciências sociais em termos da natureza de seu alcance imperial. Pode-se dizer que a economia e a ciência política são mais imperialistas, enquanto a antropologia e a sociologia são mais sensíveis ao problema da irrelevância.

Finalmente, deve ser ressaltada a necessidade de evitar o problema do auto-orientalismo (Lie, 2001: 256-257). O perigo de se passar do reconhecimento da especificidade cultural do fenômeno social para a negação da possibilidade de conceitos universais é devido à internalização de visões orientalistas por intelectuais do chamado Oriente. A visão da singularidade do Oriente é tão difundida que o mainstream das ciências sociais torna-se irrelevante, configurando uma reação extrema ao problema do orientalismo. A transformação do ponto de vista do nativo em um critério de julgamento - de tal modo que o conhecimento ocidental é rejeitado não na base de sua utilidade, força ou precisão, mas por suas origens culturais ou nacionais (Alatas, 2006: 110)-é um aspecto do problema do nativismo.

Notas

1. N. do T.: O debate sobre "the indigenization of social sciences" surgiu nos anos 1980, principalmente a partir do trabalho de intelectuais africanos e asiáticos que buscavam construir teoria sociológica a partir das crenças e formas de vida de grupos sociais não-ocidentais. Tal debate não deve ser confundido com estudos sobre populações originárias do território brasileiro, conhecidas de forma genérica no 
senso comum como "indígenas", embora haja espaço para este diálogo. Para uma referência da discussão, ver o artigo do sociólogo Akinsola Akiwowo (1999).

2. N. do T.: Farid Alatas refere-se ao conceito de "sinicization". Neste caso, optamos por uma tradução literal para facilitar a leitura.

3. O começo do movimento de sinicização nas ciências sociais taiwanesas foi marcado pela realização de uma conferência em 1982. Cf. Yan e Wen (1982) e Sun (1993).

4. Agradeço ao Dr. Hsu por traduzir algumas passagens do artigo para mim.

5. Isso ocorreu em 16 de dezembro de 1995. Entendo que a partir do número 19, o Chinese Fournal of Sociology será conhecido como Taiwanese Fournal of Sociology (comunicação do dr. Michael Hsiao HsinHuang.

6. Agradeço muito a Kwon Eun-Young pela tradução dessa e de outras passagens do coreano.

7. N. do T.: Fief (ou fee, feoff, fiefdom) sistema feudal medieval correspondia a formas de contraprestação dadas por um suserano em retribuição pela lealdade do vassalo. Geralmente tinham a forma de glebas de terra, mas podiam corresponder também a títulos de nobreza, a um direito de exploração (de caça ou pesca, por exemplo), qualquer coisa de valor doada por um senhor.

8. N. do T. Os estudos subalternos foram uma corrente historiográfica indiana cujo foco recaía na leitura e na observação do conceito gramsciano de "subalternidade" e sua aplicabilidade às sociedades do Sudeste asiático. Sua principal preocupação era restituir, em dois níveis, a voz de "grupos subalternos" que haviam sido tra- dicionalmente excluídos das narrativas da construção da nação e da memória nacional indiana: como personagens históricos relevantes e como temas da historiografia do subcontinente. $\mathrm{O}$ grupo editou uma revista homônima intitulada The Subaltern Studies, que lançou 12 números entre 1982 e 2005. O auge dessa escola deu-se nos anos 1980 , quando logrou construir fortes interlocuções com o mainstream acadêmico internacional. Muitos de seus autores dispersaram-se em universidades norte-americanas e europeias ao longo dos anos, mantendo, entretanto, vínculos de pesquisa e relações intelectuais com a academia indiana. As discussões teóricas inspiraram a releitura de várias historiografias de academias periféricas e são consideradas uma das mais importantes contribuições ao campo dos estudos pós-coloniais.

9. Kim Kyong-Dong, 21 de junho de 1996 (comunicação oral em conferência) e Kim: 1996a.

10. O número de páginas entre parênteses refere-se à tradução em inglês de Rosenthal para Muqaddimah, de Ibn Khaldūn.

11. Para uma discussão acerca da sociologia de Rizal, ver Alatas (2010) e também Rizal (1963a; 1963b; 1963c).

12. O que se segue são respostas aos comentários feitos por Michael Burawoy sobre meu Alternative Discourses in Asian Social Science (Alatas, 2006) - comunicação pessoal, 9 de janeiro de 2009.

13. Nesse trabalho discutimos a experiência dessa disciplina, concentrandonos no contexto eurocêntrico. $\mathrm{O}$ curso focava o pensamento social de Harriet Martineau, Karl Marx, Max Weber, Emile Durkheim e José Rizal. 
Referências bibliográficas

AKIWOWO, Akinsola. Indigenous Sociology: Extending the scope of the argument. International Sociology 14 (2), 1999, p. 115-138.

ALATAS, Syed Farid. On the Indigenization of Academic Discourse. Alternatives 18, 3: 307-338, 1993a.

A Khaldunian Perspective on the Dynamics of Asiatic Societies. Comparative Civilizations Review 29: 29-51, 1993 b.

Alternative Discourses in Asian Social Science: Responses to Eurocentrism, Delhi: Sage, 2006.

-_—_. Religion and Reform: Two Exemplars for Autonomous Sociology in the Non-Western Context. In: Patel, Sujata (ed.). The International Handbook of Diverse Sociological Traditions. Londres: Sage, 2010, p. 29-40.

\& Sinha, Vineeta. Teaching Classical Sociological Theory in Singapore: The Context of Eurocentrism. Teaching Sociology 29(3): 316-331.al Handbook of Diverse Sociological Traditions (ed.) Londres: Sage, 2001.

- Social Aspects of Endogenous Intellectual Creativity: The Problem of Obstacles - Guidelines for Research. In: A Abdel-Malek \& A N Pandeya (eds.). Intellectual Creativity in Endogenous Culture. Tóquio: United Nations University, 1981.

- - - The Development of an Autonomous Social Science Tradition in Asia. Asian Fournal of Social Science 30(1): 150-157, 2002.

ATAL, Yogesh. The Call for Indigenization. International Social Science Fournal 33, 1: 189-197, 1981.
BELL, Morag. Images, Myths and Alternative Geographies of the Third World. In: Derek Gregory, Ron Martin \& G. Smith (eds.). Human Geography: Society, Space and Social Science. Londres: Macmillan, 1994, p. 174-199.

BOEHMER, Elleke. Colonial and Postcolonial Literature. Oxford: Oxford University Press, 1995.

CHAN, Hoiman. Some Metasociological Notes on the Sinicisation of Sociology. International Sociology 8, 1, 113-119, 1993.

. Thoughts on the Building of a Chinese Sociological Tradition: Metasociological Notes II. Hong Kong Fournal of Social Science 3, 36-78, 1994 (original em chinês).

CHEN, Guo-Ming. Asian Communication Studies: What and Where to Now. The Review of Communication 6(4): 295-311, 2006.

- - - Beyond the Dichotomy of Communication Studies. Paper presented at International Conference on De-Westernizing Communication Research: What is the Next Step?, Taipei, Taiwan, 13-14 de dezembro de 2008.

ENRIQUEZ, Virgilio G. Towards CrossCultural Knowledge through CrossIndigenous Methods and Perspective. In: Teresita B. Obusan, Angelina R. Enriquez (eds.). Pamamaraan: Indigenous Knowledge and Evolving Research Paradigms, Quezon City: Asian Center, University of the Philippines, 1994, p. 19-31.

FAHIM, Hussein \& HELMER, Katherine. Indigenous Anthropology in Non- Western Countries: A Further Elaboration. Current Anthropology 21, 5: 644-50, 1980.

GIPOULOUX, François. Sociologie et Reforme: La Renaissance de la Sociologie en Republique Populaire de Chine. Revue 
Européenne des Sciences Sociales no. 84, 1989, p. 51-68.

GRANSOW, Bettina. Soziologie in China oder Chinesische Sozilogie? Einige Bemerkungen zum gegenwartigen Entwicklungsstand der Soziologie in der VR China. Zeitschrift fur Soziologie 14, 2, 140-151, 1985.

. Chinese Sociology: Sinicisation and Globalisation, International Sociology 8, 1, 101-112, 1993.

SANG-JIN, Han. Modernization Deficits and the Quest for a Reflexive Sociology of East Asia. Paper presented at Korean Sociological Association-International Sociological Association East Asian Regional Colloquium - "The Future of Sociology in East Asia", Seul, 22-23 de novembro, 1996.

WAN-SENG, Han. Korean Reality, Korean Sociology. Seul: Bum-Woo-Sa, 1992 (original em coreano) .

HARDY, Grant. Can An Ancient Chinese Historian Contribute to Modern Theory? The Multiple Narratives of Ssu-Ma Ch'ien. History and Theory 33(1): 20-38, 1994.

HETTNE, Björn. The Voice of the Third World: Currents in Development Thinking, Studies on Developing Countries no. 134, Budapeste: Institute for World Economics of the Hungarian Academy of Sciences, 1991.

HSU, C. K. The Formation and Transformation of a Research Paradigm: A Revisit of Prof. Chen Shao-Hsing's Article. Chinese fournal of Sociology 15, 29-40, 1991 (original em chinês).

HUANG, Wen-Shan. Collected Essays on Culturology. Cantão, 1939 (original em chinês)

- Theoretical Trends of Culturology. Taipei, 1959 (original em chinês).

nal em chinês). chinês). .

Introduction to Culturology. Hong Kong: South Sky Book Co., 1989 (original em chinês).

HUDSON, B. The New Geography and the New Imperialism, 1870-1918. Antipode 9, 12-19, 1977.

IBN KHALDâN, 'Abd al-Raimān. Muqaddimat Ibn Khalden. Beirute: Dār al-Qalam, 1378/1981.

Ibn Khaldūn: The Muqadimmah An Introduction to History, 3 vols., traduzido do árabe por Franz Rosenthal, Londres: Routledge \& Kegan Paul, 1967.

KIM, Kyong-Dong. Sociocultural Developments in the Republic of Korea. In: ROBINSON, Thomas W. (ed.). Democracy and Development in East Asia: Taiwan, South Korea, and the Philippines, Washington, DC, 1991, p. 137-154.

. Reflections on the Non-Economic Factors in Korea's Economic Development. In: KWACK, Sung Yeung (ed.). The Korean Economy at a Crossroad, Westport, CT: Praeger, 1994a, p. 41-56.

-_ Confucianism and Capitalist Development in East Asia. In: SKLAIR, Leslie. Capitalism and Development, Londres: Routledge, 1994b, p. 87-106.

. The Korean Images of Old Age: A Glimpse of Verbal Culture. Korean Fournal of Population and Development 24, 2, 1995, 173-179.

\footnotetext{
Toward Culturally "Independent" Social Science: Illustrations of Indigenization in East Asia. Paper apresentado ao Korean Sociological AssociationInternational Sociological Association East Asian Regional Colloquium - "The Future of Sociology in East Asia", Seul, 22-23 de novembro, 1996 .
} 
KUO, E.C.Y. Beyond Ethnocentrism in Communication Theory: Towards a Culture-centric Approach". Paper apresentado à International Conference on "DeWesternizing Communication Research: What is the Next Step?", Taipei, Taiwan, 13-14 de dezembro, 2008.

KWON, T'ae-Hwan. Seminar on Koreanizing Western Approaches to Social Science. Korea fournal, 19, 11, 20-25, 1979.

LEE Chong-Bum. Prolegomenon to the Indigenization of Public Administration. Social Science Fournal, 6, 7-26, 1979.

LEE, Rance P. L. Formulation of Relevant Concepts and Propositions for Sociological Research in Chinese Society. In: NAKANE, Chie Nakane \& CHAO, Chien (eda). Home Bound: Studies in East Asian Society. Tóquio: Centre for East Asian Cultural Studies, 1992, p. 81-98.

LIE, John. Ruth Benedict's Legacy of Shame: Orientalism and Occidentalism in the Study of Japan. Asian Fournal of Social Science 29, 2, 2001, p. 249-261.

LIN, Nan. Sinisation de la Sociologie: L'etape suivante. Revue Européenne des Sciences Sociales 76, 1987, p. 127-139.

PRAKASH, Gyan. Postcolonial Criticism and Indian Historiography. Social Text 31/32, 8-19, 1992.

RIZAL, José. Filipino Farmers, Political and Historical Writings. Manila: National Historical Institute, p. 19-22, 1963a.

The Truth for All, Political and Historical Writings. Manila: National Historical Institute, p. 31-38, 1963 b.

. The Indolence of the Filipino, Political and Historical Writings. Manila: National Historical Institute, p. 111-139, $1963 c$.

SARKAR, Benoy Kumar. Chinese Religion through Hindu Eyes. Nova Delhi: Asian Educational Services, 1916/1988
SCHMUTZ, Georges M.. Sociologie de la Chine ou Sociologie Chinoise? Revue Européenne des Sciences Sociales 27, 84, p. 5-17, 1989.

SHIN, Yong-Ha. Suggestions for the Development of a Creative Korean Sociology. In: Korean Sociological Association, Korean Sociology in the 21st Century, Seul: Moon-Hak-Kwa Ji-Seong-Sa, 1994, p. 15-30 (original em coreano).

SPIVAK, Gayatri Chakravorty. Subaltern Studies: Deconstructing Historiography. In: In Other Worlds: Essays in Cultural Politics. Nova York \& Londres: Routledge, 1987, p. 197-221.

SOROKIN, Pitirim A. Sociological Theories of Today. Nova York: Harper \& Row, 1966.

TAYLOR, Peter J. Full Circle or New Meaning for Global. In: JOHNTON, R. J. (ed.). The Challenge for Geography: $A$ Changing World, A Changing Discipline, Oxford: Blackwell, 1993, p. 181-197.

TURCHIN, Peter. Complex Population Dynamics: A Theoretical/Empirical Synthesis. Princeton: Princeton University Press, 2003.

— \& HALL, Thomas D. Spatial Synchrony Among and within WorldSystems: Insights from Theoretical Ecology. Fournal of World-Systems Research 9(1): 37-64, 2003. http://jwsr.ucc.edu

WITTFOGEL, Karl. Oriental despotism: a comparative study of total power. New Haven: Yale University Press, 1957.

YANG, Gan. The Inception of Chinese Social Theory: Peasant Life in China Reconsidered. Hong Kong Fournal of Social Sciences 3: 23-35, 1994 (original em chinês).

ZAWIAH, Yahya. Resisting Colonialist Discourse. Bangi: Penerbit Universiti Kebangsaan Malaysia, 1994. 


\section{Resumo}

$\mathrm{O}$ artigo parte do problema da dependência acadêmica e a forma como isso afeta as Ciências Sociais de maneira universal. Farid Alatas indica que os acadêmicos pouco podem fazer a respeito das dimensões estruturais e materiais dessa dependência, pois não estão no comando das instituições e do Estado. Contudo, sugere que há muito a fazer nos níveis intelectual e teórico. $\mathrm{O}$ artigo apresenta o conceito de discursos alternativos como fonte para uma ciência social autônoma e criativa. Estes discursos acreditam-se alternativos ao que consideram ser o caráter orientalista ou eurocêntrico das ciências sociais do Norte, das quais a estrutura das ciências sociais do Sul é dependente. $\mathrm{O}$ artigo fornece exemplos do que podem ser considerados discursos alternativos, levando em conta outras modalidades de narrativa e imaginação da vida social.

Palavras-chave: discursos alternativos; teoria social; eurocentrismo.

\section{Abstract}

The article departs from the problem of academic dependency and how does it affect social sciences globally. Farid Alatas suggests that scholars cannot do much at the structural or material level of academic dependency as they are neither in charge of institutions nor the state. However, there is more that can be done at the intellectual or theoretical level. The article presents the concept of alternative discourses as source for a creative and autonomous social science. These are discourses that present themselves as alternatives to what they regard as the Orientalist or Eurocentric social sciences of the North on which the Southern social sciences are dependent. Examples of what may be considered as alternative discourses are provided, taking into account other types of narrative and imagination of social life.

Key words: alternative discourses; social theory; Eurocentrism.

\section{Résumé}

Larticle a comme point de départ la dépendance académique et la façon comment cela affecte universellement les sciences sociales. Farid Alatas signale que les académiciens ne peuvent presque rien faire par rapport aux dimensions structurelles et matérielles de cette dépendance, puisqu'ils ne sont pas aux commandement des institutions d'État. Par contre, il sugère qu'il y a beaucoup à faire aux niveaux intellectuel et téorique. L'article présente le concept de discours alternatifs comme source pour une science sociale autonome et créative. Ces discours se croient alternatifs par rapport à ce qu'ils 
considèrent être le caracter orientaliste, ou eurocentrique, des sciences sociales du Nord, desquelles la structure des sciences sociales du Sud est dépendante. L'article fournit des exemples de ce qui peut être consideré discours alternatif, considérant d'autres modalités de narration et imagination de la vie sociale.

Mots-clés: discours alternatifs; téorie sociale; eurocentrisme. 